\title{
Best Customer Selection Decision Support System With Elimination And Choise Translation Reality (Electre) Method
}

\author{
Martinus Giawa $^{1}$, Paska Marto Hasugian ${ }^{2}$ \\ ${ }^{1,2}$ Informatics Engineering Study Program, STMIK Pelita Nusantara, Jl. Iskandar Muda No. 1 \\ Medan, Nort Sumatra, Indonesia, 20154 \\ E-mail: martinusgiawa@gmail.com

\begin{abstract}
Currently, many companies still use manual in doing any one of them is an office job CV. Independent cooperative. Based on the results of research on the CV. Koperasi Mandiri to determine the best customer still does not have a conventional and special methods and are less effective. Based on the results of this research make customer Election Decision Support System Best with ELECTRE method. Where the method ELECTRE perform testing based on criteria sort by value and ranking obtained using pairwise comparison of alternatives based on any appropriate criteria.
\end{abstract}

Keywords : Decision Support Systems, ELECTRE, Selection of the best customers.

\section{Introduction}

Advances in information technology is growing in all aspects of life in its application can facilitate the job of man, and the more opportunities and challenges within an organization or company to obtain its objectives. One important factor that is fundamental to achieve the goal of a company is the role of the Human Resources (HR) quality and high performance that was instrumental in the company to achieve the objective, therefore, companies need to know and evaluate how much potential Human Resources owned and continually strive to improve the quality of Human Resources (HR), which can be measured from the performance appraisal customer to choose the best customers.

$\mathrm{CV}$. Koperai Mandirione of the lending and borrowing located at Jl. Pemasyaraktan cape gusta Terrain Yang has customers with an unlimited number. In the selection of the best in the Company's customers obtained by the assessment team that is a leader directly based on criteria specified by the Company. The problems that exist in the company to determine client selection best is conventional and does not have special methods to resolve this problem and selection of election nasaah best is still less effective, so the authors would like to help in the process of data processing will be constructed decision support system for client selection the best method ELECTRE.

\section{Theory}

\subsection{Decision Support Systems (DSS)}

McLeod DSS is a system producing information aimed at a problem that must be made by the manager, untukmempermudahpekerjakaryawan. (Dr.Heny Pratiwi 2016). Moore and Chang (2014), CMS can be described as a system capable of supporting the data analysis and decision modeling, decision-oriented, the orientation of future planning and are used at times of unusual .. Radiant and colleagues (2016) DSS is an interactive system which supported the decision in the decision making process through alternatives derived from the processing of data, information and design of the model.

\subsection{Methods ELECTRE}

ELECTREis one of multiple criteria decision making method based on the concept of outranking using pairwise comparison of alternatives based on any appropriate criteria. (Dr.Heny Pratiwi, 2016). The procedure is done to solve the problem using ELECTRE method is as follows

\section{a. Normalizing the decision matrix.}

In this step, each attribute is converted into value xij can be done with the formula:

$\boldsymbol{r}_{i j}=\frac{x_{i j}}{m_{i=1}^{m} x_{i j}^{2}}$ for $\mathrm{i}=1,2,3, . ., \mathrm{m}$ and $\mathrm{j}=1,2,3, . ., \mathrm{n}$.

Thus obtained $\mathrm{R}$ result of normalization,

$$
r_{11} r_{12} \ldots r_{1 n}
$$

$\mathrm{R}=r_{21} r_{22} \ldots r_{2 n}$

$r_{m 1} r_{m 2} \ldots r_{m n}$ 
b. Weighted matrix that has been normalized.

Once normalized, each column of the matrix R multiplied by the weights () specified by the decision maker. Thus, the normalized weighted matrix is $\mathrm{V}=\mathrm{RW}$ written as: $w_{j}$

$$
\begin{aligned}
& \mathbf{V}=\mathbf{R W} \\
& v_{11} \quad v_{12} \ldots v_{1 n} \quad w_{1} r_{11} w_{2} r_{12} \ldots w_{n} r_{1 n} \\
& v_{21} v_{22} \ldots v_{2 n}=w_{1} r_{21} w_{2} r_{22} \ldots w_{n} r_{2 n} \\
& v_{m 1} v_{m 2} \ldots v_{m n} \quad w_{1} r_{m 1} w_{2} r_{m 2} \ldots w_{n} r_{m n} \\
& \text { Where } \mathrm{W} \text { is: } \\
& w_{1} 0 \ldots 0 \\
& \mathrm{~W}=0 w_{2} \ldots 0 \\
& \begin{array}{llll}
0 & 0 & \ldots & w_{n}
\end{array}
\end{aligned}
$$

c. Determining the set of concordance and disordance index. For each pair of alternatives $\mathrm{k}$ and $\mathrm{I}(\mathrm{k}, \mathrm{I}=1,2,3, \ldots, \mathrm{m}$ and $\mathrm{k} \neq \mathrm{I})$ collect $\mathrm{J}$ criteria are divided into two subsets, namely concordance and disordance. An alternative criteria in including concordance if:

$C_{k l}=j, v_{k j} \geq v_{l j}$, Employs to $=1,2,3, \ldots \mathrm{n}$

Instead, complementary subsets of concordance is set disordance, namely when:

$D_{k l}=j, v_{k j}<v_{l j}$, Employs to $=1,2,3, \ldots \mathrm{n}$

\section{d. Calculating the matrix concordance and disordance}

1) Counting concordance

To determine the value of the elements in concordance matrix is by adding weights are included in the set of concordance, is mathematical is as follows:

$C_{k l}=j \otimes C_{k l} W_{j}$

2) Calculating the matrix disordance

To determine the value of the elements in the matrix disordance is by dividing the maximum difference of criteria which included into subsets disordance with a maximum difference in the value of all the criteria, it mathematically is as follows:

$D_{k l}=\frac{\max \left|v_{k j}-v_{l j}\right| j \otimes D_{k l}}{\max \left|v_{k j}-v_{l j}\right| \nabla j}$

3) Determine the dominant matrix of concordance and disordance

e. Calculating the dominant matrix concordance

The matrix F as dominant concordance matrix can be constructed with the aid of a threshold value, ie by comparing each value of the matrix element concordance with the threshold value.

$\boldsymbol{C}_{\boldsymbol{k} \boldsymbol{l}} \geq \underline{\mathrm{c}}$

With a threshold value (c) are:

$\mathrm{C}=\frac{\underset{k=1}{m} \stackrel{m}{l=1}_{m} C_{k l}}{m m-1}$

So that the matrix elements $\mathrm{F}$ is determined as follows:

$f_{k l}=1, j i k a C_{k l} \geq C$

$f_{k l}=0, j i k a C_{k l}<C$

Calculating the dominant matrix disordance

Matrix $G$ sebegai disordance dominant matrix can be constructed with the aid of a threshold value:

$\underline{\mathrm{D}}=\frac{\underset{k=1}{m} \stackrel{m}{l=1} \boldsymbol{d}_{k l}}{m m-1}$

And elements of the matrix $\mathrm{G}$ is determined as follows:

$g_{k l}=1, j i k a d_{k l} \geq d$

$g_{k l}=$, jika $d_{k l}<d$

f. Determining aggre $\overline{g a t e}$ matrix dominance.

Specifying E as aggregate dominance matrix is a matrix which each element is the multiplication between the matrix elements $\mathrm{F}$ with the corresponding elements of the matrix $\mathrm{G}$, mathematically can be expressed as:

$e_{k l}=\mathbf{x} f_{k l} g_{k l}$

g. The elimination of the less favorable alternative.

The matrix E gives the preferred order of each alternaatif, namely when $e_{k l}=1$ then the alternative is better than the alternative. Thus, rows in a matrix $\mathrm{E}$ which has the fewest number $=1 \mathrm{can}$ be eliminated. Thus, the best alternative is that dominates other alternatives. $A_{k} A_{1} e_{k l}$ 


\section{Analysis}

Client selection best discussion stage on the CV. Koperasi Mandiri, first is to determine and plan the criteria for the selection of the best customers in accordance with the respective alternatives.

ELECTRE method considers all the criteria are criteria of profit, therefore, in this case, then all the criteria considered criteria profits. Here are the best customer criteria shown in Table 1.

Table 1.

Best customer Selection Criteria

\begin{tabular}{ccl}
\hline No. & code Criteria & \multicolumn{1}{c}{ name Criteria } \\
\hline 1 & C1 & Net of credit \\
2 & C2 & Total loans \\
3 & C 3 & Income \\
4 & C4 & security \\
\hline
\end{tabular}

Rating determine the suitability of each alternative on each criterion, rated with one to five, namely: $1=$ very poor $2=3=4=$ Pretty Good $5=$ Very good. The table below shows the rating the suitability of each alternative on each criterion.rating suitability for each criterion are shown in Table 2 to Table 6.

Table 2.

Job Performance Criteria

\begin{tabular}{cccl}
\hline No & Scale & Score & \multicolumn{1}{c}{ Information } \\
$\cdot$ & $0-45$ & 1 & Very bad \\
\hline 1 & $46-55$ & 2 & Bad \\
2 & $56-65$ & 3 & Enough \\
3 & $66-75$ & 4 & Well \\
4 & & & \\
\hline
\end{tabular}

Table 3.

Criteria Work Attitude

\begin{tabular}{cccl}
\hline No & Scale & Score & Information \\
\hline & $0-45$ & 1 & Very bad \\
\hline 1 & $46-55$ & 2 & Bad \\
3 & $56-65$ & 3 & Enough \\
4 & $66-75$ & 4 & Well \\
5 & $76-100$ & 5 & Very good \\
\hline
\end{tabular}

Table 4.

Criteria Cooperation

\begin{tabular}{cccl}
\hline No. & Scale & Score & \multicolumn{1}{c}{ Information } \\
\hline 1 & $0-45$ & 1 & Very bad \\
2 & $46-55$ & 2 & Bad \\
3 & $56-65$ & 3 & Enough \\
4 & $66-75$ & 4 & Well \\
5 & $76-100$ & 5 & Very good \\
\hline
\end{tabular}

Table 5.

Discipline criteria

\begin{tabular}{cccl}
\hline No. & Scale & Score & \multicolumn{1}{c}{ Information } \\
\hline 1 & $0-45$ & 1 & Very bad \\
2 & $46-55$ & 2 & Bad \\
3 & $56-65$ & 3 & Enough \\
4 & $66-75$ & 4 & Well \\
5 & $76-100$ & 5 & Very good \\
\hline
\end{tabular}

Table 6.

criteria Loyalty

\begin{tabular}{cccl}
\hline No. & Scale & Score & \multicolumn{1}{c}{ Information } \\
\hline 1 & $0-45$ & 1 & Very bad \\
2 & $46-55$ & 2 & Bad \\
3 & $56-65$ & 3 & Enough \\
4 & $66-75$ & 4 & Well \\
\hline
\end{tabular}


In this study, the sample data used as an alternative best prospective customer to perform manual calculations with ELECTRE method. In the selection of the best customers and showed the value of each alternative on the criteria of each sample are shown in Table 7.

Table 7.

rating the suitability of each alternative on each criterion

\begin{tabular}{clccccc}
\hline \multicolumn{3}{l}{$\begin{array}{l}\text { Alternativ } \\
\text { No. }\end{array}$} & \multicolumn{5}{c}{ Criteria } \\
\hline & & C1 & C2 & C3 & C4 & C5 \\
1 & A1 & 5 & 3 & 3 & 3 & 2 \\
2 & A2 & 4 & 4 & 3 & 4 & 4 \\
3 & A3 & 4 & 4 & 3 & 3 & 4 \\
4 & A4 & 2 & 4 & 3 & 3 & 4
\end{tabular}

The stages in the process of ELECTRE are steps in the run using ELECTRE methods are:

a. Normalization Decision Matrix

At this stage of the normalization of the decision matrix as in equation (2.1).

$$
\begin{aligned}
& \mathrm{R} 11=\frac{\mathrm{X} 11}{\mathrm{~m}_{\mathrm{m}}^{\mathrm{N}}=1 \mathrm{X}^{2} \mathrm{i} 1}=\frac{5}{5^{2}+4^{2}+4^{2}+2^{2}}=\frac{5}{7,81025}=0,6402 \\
& \mathrm{R} 21=\frac{\mathrm{X} 21}{\mathrm{~m}_{\mathrm{i}}^{\mathrm{m}}=1 \mathrm{X}^{2} \mathrm{i} 1}=\frac{4}{5^{2}+4^{2}+4^{2}+2^{2}}=\frac{4}{7,81025}=0,5121 \\
& \mathrm{R} 31=\frac{\mathrm{X} 31}{\mathrm{~m}_{\mathrm{i}}^{\mathrm{m}}=1 \mathrm{X}^{2} \mathrm{i} 1}=\frac{4}{5^{2}+4^{2}+4^{2}+2^{2}}=\frac{4}{7,81025}=0,5121 \\
& \mathrm{R} 41=\frac{\mathrm{X} 41}{\mathrm{~m}_{\mathrm{i}}=1 \mathrm{x}_{\mathrm{i} 1}}=\frac{2}{5^{2}+4^{2}+4^{2}+2^{2}}=\frac{2}{7,81025}=0,2561 \\
& \mathrm{R} 12=\frac{\mathrm{X} 12}{{ }_{\mathrm{i}}^{\mathrm{m}}=1 \mathrm{X}^{2} \mathrm{i} 2}=\frac{3}{3^{2}+4^{2}+4^{2}+4^{2}}=\frac{3}{7,81025}=0,3974 \\
& \mathrm{R} 22=\frac{\mathrm{x} 22}{{ }_{\mathrm{i}}^{\mathrm{m}}=1 \mathrm{X}^{2} \mathrm{i} 2}=\frac{4}{3^{2}+4^{2}+4^{2}+4^{2}}=\frac{4}{7,81025}=0,5298 \\
& \mathrm{R} 32=\frac{\mathrm{x} 32}{\mathrm{~m}_{\mathrm{i}}^{\mathrm{m}}=1 \mathrm{X}^{2} \mathrm{i} 2}=\frac{4}{3^{2}+4^{2}+4^{2}+4^{2}}=\frac{4}{7,81025}=0,5298
\end{aligned}
$$

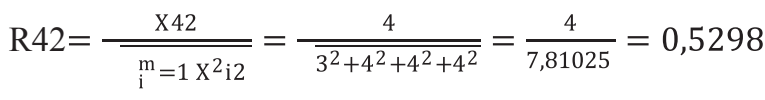

$$
\begin{aligned}
& \mathrm{R} 13=\frac{\mathrm{x} 13}{\mathrm{i}_{\mathrm{i}}^{\mathrm{m}}=1 \mathrm{x}^{2} \mathrm{i} 3}=\frac{3}{3^{2}+3^{2}+3^{2}+3^{2}}=\frac{3}{6}=0,5 \\
& \mathrm{R} 23=\frac{\mathrm{x} 23}{\mathrm{i}_{\mathrm{i}}^{\mathrm{m}}=1 \mathrm{x}^{2} \mathrm{i} 3}=\frac{3}{3^{2}+3^{2}+3^{2}+3^{2}}=\frac{3}{6}=0,5 \\
& \mathrm{R} 33=\frac{\mathrm{x} 33}{\mathrm{i}_{\mathrm{i}}^{\mathrm{m}}=1 \mathrm{x}^{2} \mathrm{i} 3}=\frac{3}{3^{2}+3^{2}+3^{2}+3^{2}}=\frac{3}{6}=0,5 \\
& \mathrm{R} 43=\frac{\mathrm{X} 43}{\mathrm{i}_{\mathrm{i}}^{\mathrm{m}}=1 \mathrm{X}^{2} \mathrm{i} 3}=\frac{3}{3^{2}+3^{2}+3^{2}+3^{2}}=\frac{3}{6}=0,5 \\
& \mathrm{R} 14=\frac{\mathrm{x} 14}{\mathrm{i}_{\mathrm{i}}^{\mathrm{m}=1 \mathrm{x}^{2} \mathrm{i} 4}}=\frac{3}{3^{2}+4^{2}+3^{2}+3^{2}}=\frac{3}{6,557}=0,4575 \\
& \mathrm{R} 24=\frac{\mathrm{x} 24}{\mathrm{~m}_{\mathrm{i}}=1 \mathrm{x}^{2} \mathrm{i} 4}=\frac{4}{3^{2}+4^{2}+3^{2}+3^{2}}=\frac{4}{6,557}=0,610 \\
& \mathrm{R} 34=\frac{\mathrm{X} 34}{\mathrm{~m}_{\mathrm{i}=1 \mathrm{x}^{2} \mathrm{i} 4}}=\frac{3}{3^{2}+4^{2}+3^{2}+3^{2}}=\frac{3}{6,557}=0,4575 \\
& \mathrm{R} 44=\frac{\mathrm{X} 44}{{\underset{\mathrm{i}}{\mathrm{m}}=1 \mathrm{x}^{2} \mathrm{i} 4}}=\frac{3}{3^{2}+4^{2}+3^{2}+3^{2}}=\frac{3}{6,557}=0,4575 \\
& \mathrm{R} 15=\frac{\mathrm{x} 15}{\frac{\mathrm{m}_{\mathrm{i}}=1 \mathrm{x}^{2} \mathrm{i} 5}{2^{2}+4^{2}+4^{2}+4^{2}}}=\frac{2}{7,211}=0,2774
\end{aligned}
$$




$$
\begin{aligned}
& \mathrm{R} 25=\frac{\mathrm{X} 25}{{ }_{\mathrm{i}}^{\mathrm{m}}=1 \mathrm{X}^{2} \mathrm{i} 5}=\frac{4}{2^{2}+4^{2}+4^{2}+4^{2}}=\frac{4}{7,211}=0,5475 \\
& \mathrm{R} 35=\frac{\mathrm{X} 35}{{ }_{\mathrm{i}}^{\mathrm{m}=1 \mathrm{X}^{2} \mathrm{i} 5}}=\frac{4}{2^{2}+4^{2}+4^{2}+4^{2}}=\frac{4}{7,211}=0,5475 \\
& \mathrm{R} 45=\frac{\mathrm{X} 45}{{ }_{\mathrm{i}}^{\mathrm{m}}=1 \mathrm{X}^{2} \mathrm{i} 5}=\frac{4}{2^{2}+4^{2}+4^{2}+4^{2}}=\frac{4}{7,211}=0,5475
\end{aligned}
$$

From the above calculation matrix obtained as follows: $0,64020,39740,50,45750,2774$

$R=0,51210,52980,5 \quad 0,610,5475$

$0,51210,52980,50,45750,5475$

$0,25610,52980,50,45750,5475$

Table 8

Normalization matrix

\begin{tabular}{ccccccc}
\hline No. & $\begin{array}{c}\text { Alternativ } \\
\mathbf{e}\end{array}$ & C1 & C2 & C3 & C4 & C5 \\
\hline 1 & A1 & .6402 & .3974 & 0.5 & .4575 & .2774 \\
2 & A2 & .5121 & .5298 & 0.5 & 0.61 & .5547 \\
3 & A3 & .5121 & .5298 & 0.5 & .4575 & .5547 \\
4 & A4 & .2561 & .5298 & 0.5 & .4575 & .5547 \\
\hline
\end{tabular}

Then the user will be determining the weights for each criterion. Examples of weight values that the user entered example is as follows:

Table 9

table Weight

\begin{tabular}{|l|r|r|r|r|r|}
\hline Criteria & $\mathrm{C} 1$ & $\mathrm{C} 2$ & $\mathrm{C} 3$ & $\mathrm{C} 4$ & $\mathrm{C} 5$ \\
\hline weight & 5 & 2 & 4 & 2 & 5 \\
\hline
\end{tabular}

b. Weighting On That Has Normalized Matrix

Unknown Weight possessed of every individual - each criterion with equation (2.2) are:

$\mathrm{W}=(5,2,4,2,5)$

$\mathrm{V} 11=\mathrm{R} \times \mathrm{W}=0.6402 \times 5=3.2009$

$\mathrm{V} 21=\mathrm{R} \times \mathrm{W}=0.5121 \times 5=2.5607$

$\mathrm{V} 31=\mathrm{R} \times \mathrm{W}=0.5121 \times 5=2.5607$

$\mathrm{V} 41=\mathrm{R} \times \mathrm{W}=0.2561 \times 5=1.2804$

$\mathrm{V} 12=\mathrm{R} \times \mathrm{W}=0.3974 \times 2=0.7947$

$\mathrm{V} 22=\mathrm{R} \times \mathrm{W}=0.5298 \times 2=1.0596$

$\mathrm{V} 32=\mathrm{R} \times \mathrm{W}=0.5298 \times 2=1.0596$

$\mathrm{V} 42=\mathrm{R} \times \mathrm{W}=0.5298 \times 2=1.0596$

$\mathrm{V} 13=\mathrm{R} \times \mathrm{W}=0.5 \times 4=2$

$\mathrm{V} 23=\mathrm{R} \times \mathrm{W}=0.5 \times 4=2$

$\mathrm{V} 33=\mathrm{R} \times \mathrm{W}=0.5 \times 4=2$

$\mathrm{V} 43=\mathrm{R} \times \mathrm{W}=0.5 \times 4=2$

$\mathrm{V} 14=\mathrm{R} \times \mathrm{W}=0.4575 \times 2=0.915$

$\mathrm{V} 24=\mathrm{R} \times \mathrm{W}=0.61 \times 2=1,220$

$\mathrm{V} 34=\mathrm{R} \times \mathrm{W}=0.4575 \times 2=0.915$

$\mathrm{V} 54=\mathrm{R} \times \mathrm{W}=0.4575 \times 2=0.915$

$\mathrm{V} 15=\mathrm{R} \times \mathrm{W}=0.2774 \times 5=1.3868$

$\mathrm{V} 25=\mathrm{R} \times \mathrm{W}=0.5547 \times 5=2.7735$

$\mathrm{V} 25=\mathrm{R} \times \mathrm{W}=0.5547 \times 5=2.7735$

$\mathrm{V} 45=\mathrm{R} \times \mathrm{W}=0.5547 \times 5=2.7735$

From the above calculation matrix obtained as follows:

$$
3,20090,794720,9151,3868
$$

$\mathrm{V}=2,56071,059621,2202,7735$

$=2,56071,059620,9152,7735$

$1,28041,059620,9152,7735$

c. Determine the Association of Concordance and Discordance on

Index 